\title{
Distribution and Biotechnological Applications of Chitinase: A Review
}

\author{
Garima Dukariya, Anil Kumar* \\ School of Biotechnology, Devi Ahilya University, Khandwa Rd., Indore-452001, India
}

Received June 25, 2020; Revised August 1, 2020; Accepted August 25, 2020

\section{Cite This Paper in the following Citation Styles}

(a): [1] Garima Dukariya, Anil Kumar , "Distribution and Biotechnological Applications of Chitinase: A Review," International Journal of Biochemistry and Biophysics, Vol. 8, No. 2, pp. 17 - 29, 2020. DOI: 10.13189/ijbb.2020.080201.

(b): Garima Dukariya, Anil Kumar (2020). Distribution and Biotechnological Applications of Chitinase: A Review. International Journal of Biochemistry and Biophysics, 8(2), 17 - 29. DOI: 10.13189/ijbb.2020.080201.

Copyright $\odot 2020$ by authors, all rights reserved. Authors agree that this article remains permanently open access under the terms of the Creative Commons Attribution License 4.0 International License

\begin{abstract}
Chitinases are a group of hydrolytic enzymes catalysing degradation of chitin, the second most abundant polysaccharide in nature. Chitin is an essential structural component of most fungi cell walls, and exoskeleton of insects and crustaceans. Chitinases are synthesized in wide variety of organisms including plants, vertebrates, invertebrates, microbes (bacteria and fungi) and viruses. They perform various functions in different organisms depending upon the requirement of organisms like defense against pathogens and nutritional purpose. Nowadays chitinolytic enzymes have attracted global attention because of their different biotechnological and biomedical applications due to their hydrolytic activity on chitin and thus several chitinases have been reported and characterized. They are used mainly for biodegradation of chitin into beneficial compounds. These compounds have been illustrated to enhance human health through their antimicrobial, antioxidant, antitumor and anti-inflammatory properties. Chitinases have also been exploited for bio-control of phytopathogens and insects. Apart from these, the crucial use of chitinases in present time is in management of chitinous waste thus they have the potential to become essential tools in future green application. The present review focuses on the occurrence and varied distribution of chitinases. Here we also took a closer look at recent applications of chitinase in various fields.
\end{abstract}

Keywords Chitin, Chitinases, Glycosyl Hydrolase, Waste Management, Biocontrol

\section{Introduction}

Living organisms have complex network of chemical reactions catalyzed by specific enzymes. Enzymes are biological catalysts having remarkable efficiency and specificity. A large number of enzymes have been discovered and studied since concept of enzymes was given in nineteenth century [1]. Life can't be considered without enzymes. Besides, many enzymes have also been exploited for various commercial purposes. With advancement in the field of biotechnology, importance of enzymes increased enormously in various industrial sectors and studies are also being carried out at the molecular level. With progress in various fields of biological science like genetics, protein engineering and bioinformatics, a new epoch of enzyme applications in many industrial processes became possible [2].

Chitin is world's second most abundant carbon reserve in nature [3]. It is a renewable natural source and is an inelastic linear homopolymer having $\mathrm{N}$-acetyl glucosaminyl residues linked through $\beta-1,4$ linkages [4,5]. It is the main structural component of exoskeleton in invertebrates like insects and crustaceans and has also been found in the cell wall of many fungi [6,7]. With advancement, it has been shown that chitin and its derivatives are of pharmaceutical and other industrial importance. Chitin has been shown to exhibit antimicrobial, anti-cholesterol and antitumor activities. Besides, it has also been shown to play important role in treatment of waste water, drug delivery, healing wounds and dietary fibers [8,9]. Because of its various applications, it has got immense attention in fields of pharmacology, agriculture 
and biotechnology [6].

The most important chitin degrading enzyme is chitinase which breaks $\beta-1,4$ glycosyl linkages randomly in chitin and produces $\mathrm{N}$-acetylglucosamine $\left(\mathrm{Gl}_{\mathrm{C}} \mathrm{NA} \mathrm{A}_{\mathrm{C}}\right)$ and its various oligomers of different length. Commercially, chitin is degraded into smaller products by using acid treatment. However, with awareness of environmental pollution, it is not a method of choice and there is need of searching more environment friendly method(s). Enzymatic degradation of chitin using chitinase enzyme being eco-friendlier may be a better choice [10].

The generation of chitinous wastes from the global production and processing of fish scales and shell-fish is a severe issue which may create threat for environment due to its accumulation [11]. Majority of sea food industries have a plethora of chitinous waste. Chitin is produced globally in the aquatic biosphere in extensive amount every year but in ocean sediments there is no high aggregation of chitin waste as it is efficiently decomposed and degraded by marine chitinase secreting microbes [12]. The chitin is converted into biological useful carbon and nitrogen forms by these microbes and recycles in marine environment [13]. Therefore, this approach can be utilized for waste management of chitin by chitinases. Because of this property of chitinase, it may also be exploited for various biotechnological applications [14]. In the present review, various aspects of chitinases including distribution, their roles in various organisms, structural and biotechnological aspects have been discussed. Besides, focus has been on the potential applications of chitinases in waste management of chitin, which can replace the chemical method of chitin degradation in the future.

\section{Classification}

Chitinase belongs to glycosyl hydrolase family. It randomly breaks glycosidic linkage in chitin molecule [15]. Chitinases are classified into two categories based on manner in which they cleave chitin and named as endo-chitinase and exo-chitinase [16]. Endo-chitinase (EC. 3.2.1.14) splits $\beta-1,4$ glycosyl linkages randomly at internal sites of chitin producing low molecular weight oligomers of $\mathrm{Gl}_{\mathrm{C}} \mathrm{NA}_{\mathrm{C}}$ such as chitotetraose, chitotriose and chitobiose while exo-chitinases split $\beta-1,4$ glycosyl linkage in chitin from non-reducing end [10] as shown in Fig.1. Exochitinases are further sub-divided into two categories on the basis of release of the product: chitobiosidase (E.C. 3.2.1.29) and $\beta-(1,4)-\mathrm{N}$-acetyl glucosaminidase (E.C 3.2.1.30). Chitobiosidase cleaves alternate $\beta-1,4$ glycosyl linkage in chitin from the non-reducing end producing chitobiose $\quad[3,17], \quad$ whereas, $\quad \beta-(1,4)-\mathrm{N}$-acetyl glucosaminidase cleaves $\beta-1,4$ glycosyl linkage in chitin from non-reducing end producing $\mathrm{Gl}_{\mathrm{C}} \mathrm{NA}_{\mathrm{C}}$ [18]. It is also capable of acting on the oligomeric products of endochitinase and chitobiosidase to produce monomer moiety and that is $\mathrm{Gl}_{C} \mathrm{NA}_{\mathrm{C}}[9,19]$. However, the IUBMB (International Union of Biochemistry and Molecular Biology) enzyme nomenclature has included both exo-chitinases (EC. 3.2.1.29 and EC. 3.2.1.30) under one enzyme known as $\beta$-N-acetylhexosaminidases (E.C. 3.2.1.52) [20] (https://www.qmul.ac.uk/sbcs/iubmb/enzy $\mathrm{me} /)$.

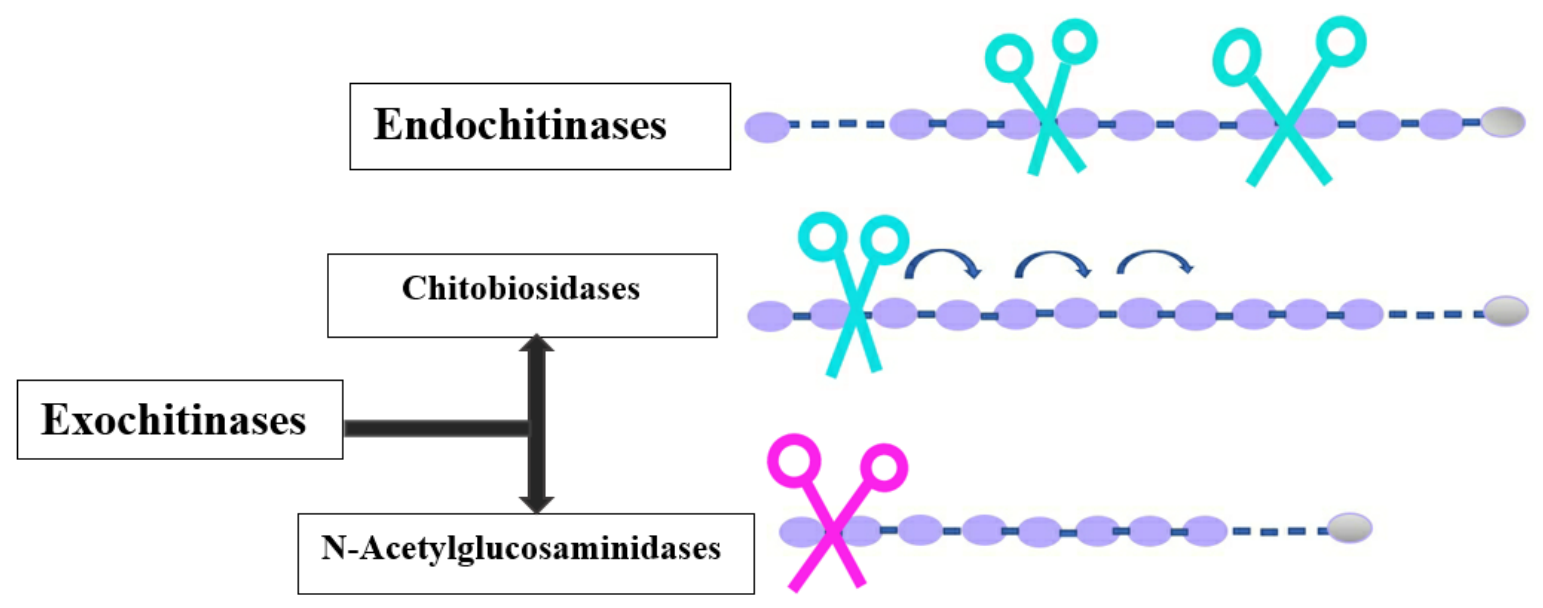

Figure1. Schematic diagram indicating cleavage patterns of chitinolytic enzymes 


\section{Structural Aspects of Chitinase}

On the basis of similarities in amino acid sequence, chitinolytic enzymes are categorized into glycosyl hydrolase (GH) families 18, 19 and 20 [3,15,21,22]. Families 18, 19 and 20 differ in many properties like structure, molecular mechanism and amino acid sequences (Table 1) indicating that they have evolved from different ancestors [4]. Barrel folds are present in family 18 chitinases while family 19 chitinases have high contents of $\alpha$-helixes. The structures of a few chitinases belonging to different families are shown in Fig.2. The other differences are in their hydrolysis mechanism, where substrateassisted catalysis occurs in family 18 chitinases and in family 19, acid base mechanism is used for hydrolysis $[2,15]$.

Chitinases from family 18 are widely distributed in bacteria, insects, plants, fungi, viruses and animals and hence are diverse in evolutionary terms. Plant and few Streptomyces chitinases are placed under family 19, while human and Streptomycetes ( $\beta$ - $\mathrm{N}$-acetylhexosaminidases) chitinases are included in family $20[2,14,23]$.

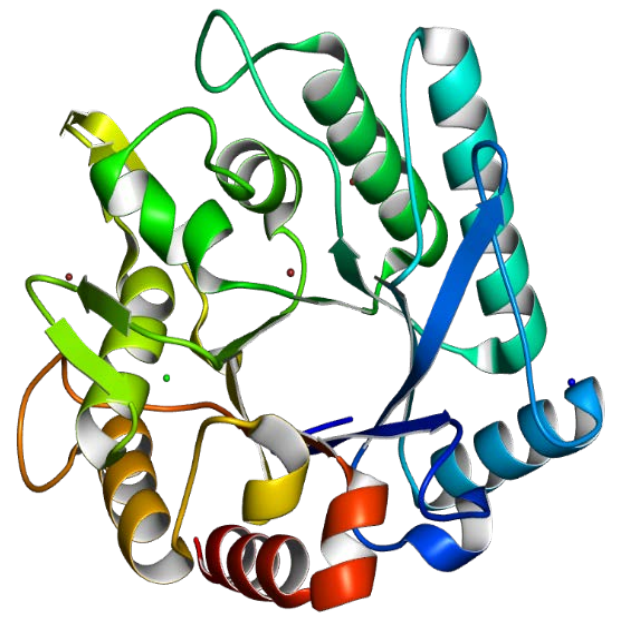

2(a): Crystal structure of Family 18 Chitinase (Bacillus anthracis)

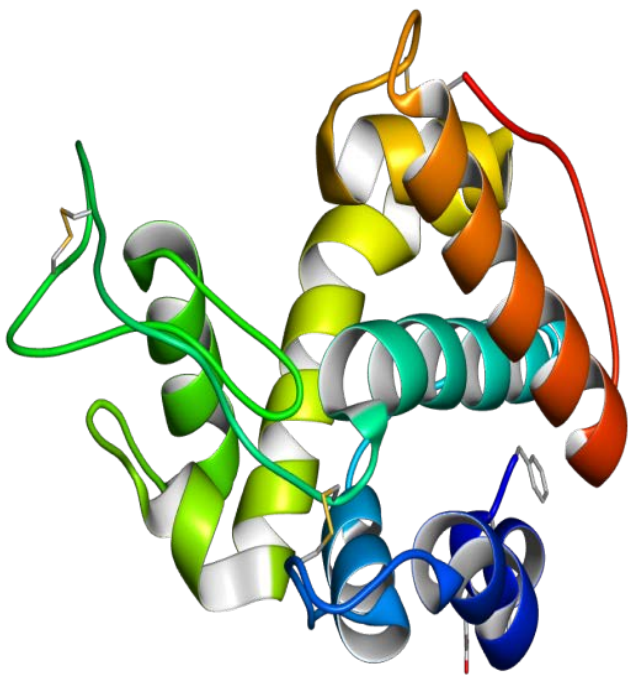

2(c): Crystal structure of Family 19 Chitinase (Zea mays)

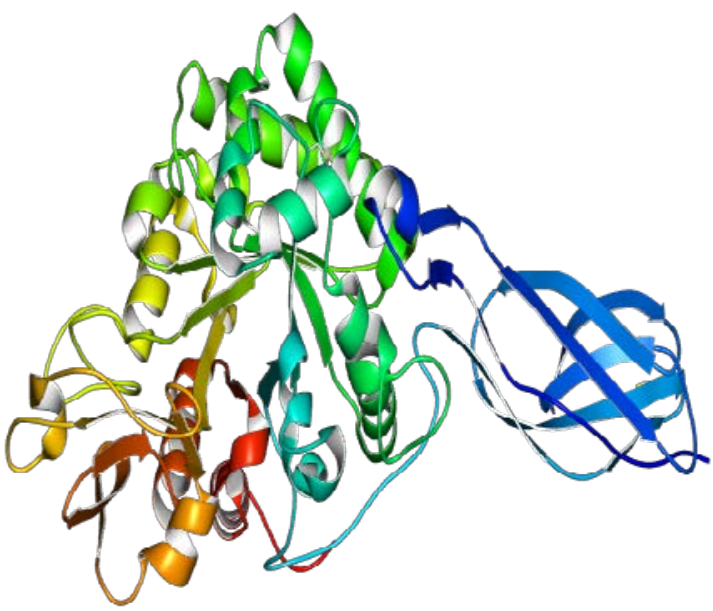

2(b): Crystal structure of Family 18 Chitinase (Serratia marcescens)

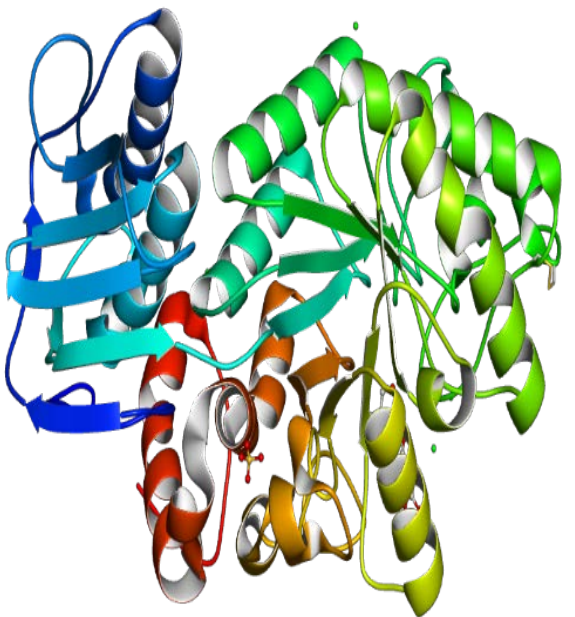

2(d): Crystal structure of Family 20 Chitinase (Streptomyces plicatus)

Figure 2. Three-dimensional structure of some chitinases belonging to different families. All the chitinase structures were retrieved from the protein data bank (PDB).

Table 1. Difference between chitinases of glycosyl hydrolases belonging to families 18, 19 and 20 [20,24].

\begin{tabular}{|c|c|c|c|c|}
\hline Glycosidase family & Classes & Occurrence & Catalytic mechanism & Structure \\
\hline 18 & III and V & $\begin{array}{c}\text { Bacteria, archaea, insects, plants, } \\
\text { fungi, viruses and animals. }\end{array}$ & Substrate - assisted & Barrel folds are present \\
\hline 19 & I, II and IV & Plants and Streptomyces & Acid- base mechanism & $\alpha$ - helixes are present \\
\hline 20 & V and VI & Bacteria, Streptomyces and humans & Substrate- assisted & Barrel folds are present \\
\hline
\end{tabular}




\section{Roles of Chitinases}

Chitinases are widely distributed in various organisms including viruses, animals, fungi, higher plants, bacteria, and insects. They have different functions in these organisms and have role in physiological and bioconversion processes. In bacteria, chitinases play different roles in parasitism, nutrition and recycling of chitin in nature [19], whereas in plants and vertebrates, they are involved in defense mechanisms against fungal pathogens. In case of fungi, protozoa, and invertebrates, they are involved in morphogenesis. Some viruses like Baculovirus also produce chitinase enzyme for pathogenesis. These enzymes also showed activity in human serum. Apart from energy source and defense, they play structural role in some arthropods and fungi [3,14,19]. Chitinase (EC. 3.2.1.14) is produced by different organisms where it plays various physiological roles (Table 2).

\section{Distribution of Chitinases}

In the last four decades, much research has been conducted on the occurrence and distribution of chitinases from different sources like bacteria, archaea, fungi, plants, insects and humans (Table 3). There are different types of chitinases depending upon the organism or source from which they are produced.

Table 2. Roles of chitinases in various organisms.

\begin{tabular}{|c|c|c|}
\hline Organism & Function(s) to produce chitinase & Reference(s) \\
\hline Bacteria & Digestion of chitin for nutrition and utilization as energy source. \\
\hline Plants & $\begin{array}{c}\text { Protection against pathogens by providing defense and in development } \\
\text { of plants }\end{array}$ & {$[25,26]$} \\
\hline Fungus & For nutritional purposes, cell wall remodeling and morphogenesis. & {$[4,27]$} \\
\hline Insects & $\begin{array}{c}\text { Defense against parasites, postembryonic development and old cuticle } \\
\text { degradation. }\end{array}$ & {$[18]$} \\
\hline Virus & Helps in pathogenesis. & {$[18,28]$} \\
\hline Mammals & Defense purposes. & \\
\hline
\end{tabular}

Table 3. List of different organisms discovered for chitinase production.

\begin{tabular}{|c|c|c|c|c|}
\hline Microbe's name & $\begin{array}{l}\text { Source of } \\
\text { isolation }\end{array}$ & $\begin{array}{c}\begin{array}{c}\text { Property of chitinase } \\
\text { secreted }\end{array} \\
\end{array}$ & Application & References \\
\hline Aspergillus terreus & Marine water & - & Pharmaceutical & [29] \\
\hline $\begin{array}{l}\text { Paenibacillus sp. and } \\
\text { Enterobacter sp. }\end{array}$ & $\begin{array}{c}\text { Fresh water } \\
\text { sediments }\end{array}$ & High molecular weight & Antifungal & {$[30]$} \\
\hline Paenibacillus elgii HOA73 & Field soil & Stability at broad $\mathrm{pH}$ range & $\begin{array}{c}\text { Agriculture (as antifungal } \\
\text { agent) }\end{array}$ & [31] \\
\hline Streptomyces coelicolor A3 & Soil & $\begin{array}{l}\text { Stability at broad } \mathrm{pH} \text { range } \\
\text { and temperature below } 55^{\circ} \mathrm{C} \text {. }\end{array}$ & NAG synthesis & [32] \\
\hline Bacillus pumilus JUBCH08 & Beach sediment & $\begin{array}{c}\text { Thermostable and alkali } \\
\text { tolerant }\end{array}$ & $\begin{array}{c}\text { Biocontrol of } \\
\text { phytopathogens }\end{array}$ & [33] \\
\hline Aspergillus awamori & Honey & Halotolerant & $\begin{array}{l}\text { Industrial importance } \\
\text { (immobilized) }\end{array}$ & [34] \\
\hline $\begin{array}{c}\text { Pseudoalteromonas sp. } \\
\text { DXK012 }\end{array}$ & $\begin{array}{c}\text { Deep sea } \\
\text { sediments }\end{array}$ & Thermostable & Industrial application & [35] \\
\hline Streptomyces hygroscopicus & Peanut plant & $\begin{array}{c}\text { Stable at broad pH range and } \\
\text { temperature }\end{array}$ & Agriculture & [36] \\
\hline $\begin{array}{l}\text { Stenotrophomonas } \\
\text { maltophilia }\end{array}$ & Rhizosphere soil & Thermostable & Antifungal & [37] \\
\hline Glaciozyma antarctica PI12 & Water & $\begin{array}{c}\text { Highly stable at low } \\
\text { temperature and acidic pH } \\
\text { range }\end{array}$ & $\begin{array}{l}\text { Industrial (production of } \\
\text { chitooligomers) }\end{array}$ & [38] \\
\hline Penicillium LYG 0704 & Field soil & Thermostable & Chitin degradation & {$[16]$} \\
\hline Ostrinia furnacalis & Midgut & Stable at high $\mathrm{pH}$ & Antifungal & [39] \\
\hline Vigna radiata & Seeds & Thermostable & $\begin{array}{c}\text { Biocontrol of } \\
\text { phytopathogens }\end{array}$ & {$[40]$} \\
\hline Trichosanthes dioica & Seeds & $\begin{array}{l}\text { Stable at wide } \mathrm{pH}(5-11) \text { and } \\
\text { temperature }\left(30-90^{\circ} \mathrm{C}\right)\end{array}$ & Antifungal & {$[41]$} \\
\hline Hippophae rhamnoides & Seedlings & Cold tolerant & Defense response & {$[42]$} \\
\hline Mus musculus & Stomach & Stable in wide $\mathrm{pH}$ range & Medical applications & [43] \\
\hline $\begin{array}{l}\text { Thermococcus chitonophagus } \\
\text { sp. }\end{array}$ & $\begin{array}{c}\text { Deep sea } \\
\text { hydrothermal vent } \\
\text { environment }\end{array}$ & Highly thermostable & Chitin degradation & {$[44]$} \\
\hline Halomicrobium sp. & Hypersaline lake & Salt tolerant & Chitin degradation & {$[45]$} \\
\hline $\begin{array}{l}\text { Thermococcus kodakarensis } \\
\text { KOD1 }\end{array}$ & Volcanic area & Thermostable & $\begin{array}{c}\text { Application in shell } \\
\text { degradation }\end{array}$ & {$[46,47]$} \\
\hline Pyrococcus furiosus & Lake & Thermostable & $\begin{array}{c}\text { Industrial (production of } \\
\text { chitooligomers) }\end{array}$ & [48] \\
\hline
\end{tabular}




\section{Bacterial Chitinases}

Bacterial chitinases have been included under glycosyl hydrolase family 18, however, Streptomyces species enzyme has been put under family 19 [3]. Chitinases from various organisms and microbes are consisted of multiple functional domains including a chitin-binding domain (enriched in cysteine), a serine/threonine- enriched glycosylated domain and a catalytic domain. The role of chitin binding domain in the hydrolysis of insoluble chitin has been investigated in some bacterial chitinases $[17,49]$. The chitin binding domain can be present either at the $\mathrm{N}$-terminal or $\mathrm{C}$-terminal end of the enzyme. Bacterial chitinases are divided into three sub-families named as $\mathrm{A}$, $\mathrm{B}$ and $\mathrm{C}$ on the basis of amino acid sequence of individual catalytic domains $[3,14,17]$. A third domain is present in subfamily A chitinases due to the insertion of an $(\alpha)$ alpha $+(\beta)$ beta fold region in between the $(\alpha / \beta)_{8}$ barrel [2]. Most of the chitinases characterized from bacteria have been classified into subfamily A, suggesting that subfamily A chitinases genes are widely distributed in nature $[17,50]$.

Role of bacterial chitinases is mainly in nutrition as they cause degradation of chitin which is utilized as an energy source $[17,51]$. Apart from this, chitinase also plays role in parasitism [24] and provides defense against pathogens [25]. Bacterial chitinases are widely distributed in species like Pseudomonas, Streptomyces, Bacillus, Aeromonas, Arthrobacter, Clostridium, Vibrio, Chromobacterium, Beneckea, Klebsiella and Serratia [15,52]. Serratia species produces high level of chitinase enzyme. Many chitinases isolated and sequenced from bacteria belong to family 18 of glycosyl hydrolases (GH) except of Streptomyces griseus 11UT6037 chitinase that has been included in family 19 [17].

The molecular weight of bacterial chitinases ranges from 20,000 to 60,000 daltons [52]. Chitinases isolated from bacteria are found to be active over wide range of $\mathrm{pH}$ and temperature depending on varieties of species. They showed enzyme activity at $\mathrm{pH}$ range 5 to 8 and optimum temperature is $40^{\circ} \mathrm{C}$. Recently, a chitinase from Bacillus cereus was isolated and produced from chitinous waste enriched soil showed optimum $\mathrm{pH} 7$ for maximum chitinolytic activity [53]. Chitinolytic enzyme of Serratia marcescens exhibited maximum activity at $32^{\circ} \mathrm{C}$ temperature and at a $\mathrm{pH}$ of 8 [9,54]. In many cases, heavy metals have been shown to influence the activity of chitinase by inhibiting enzyme activity [55].

\section{Archaea Chitinases}

In comparison to eukaryotes and bacteria, there is lesser information known about chitinases from archaea domain. However, various archaeal chitinases from hyperthermophiles and halophiles have been investigated in the last decade. In the Archaea domain, the potential to utilize chitin as a growth substrate is a distinct feature of
Thermococcus chitonophagus. A novel chitinase secreting hyperthermophilic archaeon, T. chitonophagus sp. was isolated from a deep-sea hydrothermal vent environment [44]. Thermococcus kodakarensis KOD1 is another hyperthermphilic anaerobe from which several chitinases have been isolated. For instance, Tk-ChiA is a chitinase coded by $T k 1765$ gene isolated from $T$. kodakarensis, has an optimum temperature of $80^{\circ} \mathrm{C}$. It comprises of two GH-18 catalytic domains along with C- terminal and Nterminal domains. It also consists of three substrate binding domains (CBD1, CBD2, CBD3) which bind to chitin. These chitinases produced from archaea, including Tk-ChiA, produced chitobiose as an end product after chitin degradation [46]. Recently a chitinase was cloned and purified from $T$. kodakarensis which has secondary ability for cellulose degradation also. The study reported that the dual hydrolytic activity of chitinase is due to the presence of three binding domains with affinity for cellulose and chitin. It exhibited thermal stability ranging from 70 to $80^{\circ} \mathrm{C}$ and showed $40 \%$ of maximum activity at $100^{\circ} \mathrm{C}$. It was further demonstrated that Tk-ChiA with thermostable dual hydrolytic ability may be used for hydrolysis of shell and straw waste treatment [47].

The genomes of various halo-archaea like Halobacterium salinarum, Haloferax mediterranei, Halomicrobium sp. etc. are consisted of gene(s) coding for GH-18 family chitinases. Production of extracellular highly salt tolerant chitinase was reported from a halo-archaeal strain isolated from hypersaline lake [45]. Gong and co-workers reported the hydrolysis of chitosan by recombinant chitinase of Pyrococcus furiosus, which produced chitooligosaccharides as the end product [48].

\section{Fungal Chitinases}

Chitinases from fungi have been studied more explicitly due to their important physiological and biological roles and applications in biotechnology [4]. Fungal chitinases have been placed under family 18 of glycosyl hydrolases. A characteristic feature of this family is their multi- domain structure. The basic structure of the enzyme is consisted of five domains namely $\mathrm{N}$-terminal signal peptide region, chitin binding domain, catalytic domain, serine/threonine enriched region and C-terminal extension region (Fig. 3). Only two domains, N-terminal and catalytic domains are essential for chitin degradation and most of the chitinases lack remaining three domains $[14,17]$.

These different structural domains of fungal chitinases have different biochemical functions. The catalytic domain is accountable for the substrate hydrolysis and it consists of the ' $\mathrm{N}$ ' terminal half of the enzyme. The serine/threonine- enriched region is generally glycosylated with sugar chains to produce mature protein and thus acts as glycosylation site, which may be essential for the maintenance of protein stability and its secretion. Further the chitin binding domain facilitates in anchoring to the substrate or cell wall [4,19]. 


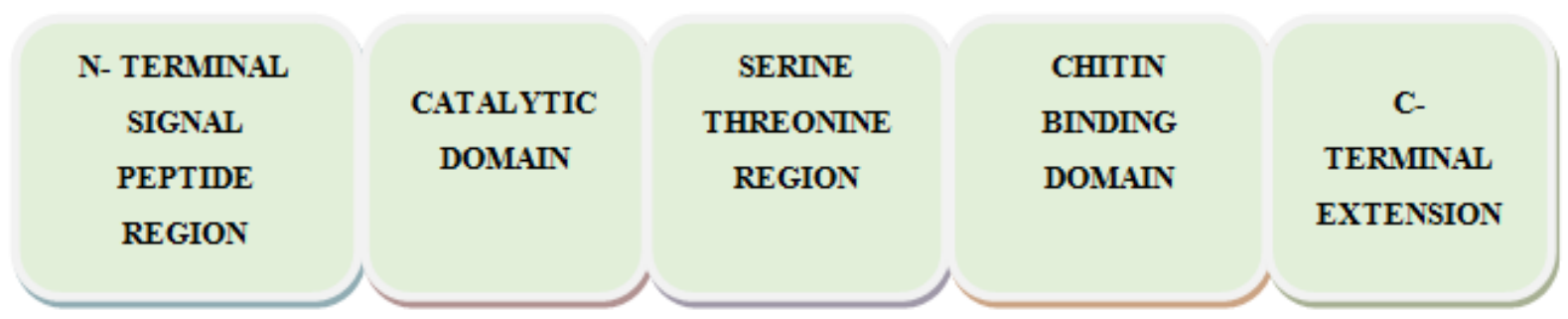

Figure 3. The basic structural domains of fungal chitinase.

A phylogenetic study of chitinases from fungal genome revealed that they are further divided into three subgroups; subgroups $\mathrm{A}$ and $\mathrm{B}$ (corresponding to class $\mathrm{V}$ and III, respectively) are consisted of all earlier identified fungal chitinases, whereas subgroup $\mathrm{C}$ is consisted of a novel group of chitinases with high molecular weight $[4,56]$.

Fungal chitinases play important role in morphogenesis, nutrition and in fungal development process. For growth of fungal hyphae, this enzyme is required [17,57]. The enzyme also has role in cell wall remodeling [56].

Fungal chitinases exhibit enzyme activity in the $\mathrm{pH}$ range of 4 to 7 and have optimum temperature in the range of 20 to $40^{\circ} \mathrm{C}$. They are highly stable and have much variable molecular weight ranging from 27,000 to 190,000 daltons [19]. It has been shown that mostly heavy metal ions like $\mathrm{Fe}^{2+}$ and $\mathrm{Hg}^{2+}$ inhibit the enzyme activity, whereas, $\mathrm{Mg}^{2+}$ are found to stimulate the enzyme activity [16]. Many copper and mercuric salts are also been shown to inhibit the enzyme. Allosamidin and demethylallosamidin are shown to inhibit enzyme activity competitively $[2,19,58]$. The compounds like chitin and $\mathrm{N}$-acetyl glucosamine are reported to act as inducer for the enzyme; and glucose and other carbon sources act as repressor $[4,14,56]$. Fungal chitinase have been shown to be more effective and active compared to the chitinases from other microbes and plants $[4,59]$.

\section{Plant Chitinases}

Plant chitinases are generally endochitinases and are found in stems, seeds, flowers and tubers. These are tissue specific and their molecular weight ranges from 20,000 to 40,000 daltons. On the basis of amino acid sequences, plant chitinases are divided into five classes. Enzymes of class I, II, and IV contain globular domains in their structure while chitinases belonging to class III and V have 8 alpha- helix and 8 beta strands [17]. Class I, II and IV are included in family 19, while III and V class chitinase belongs to family 18 [14].

Plant chitinases considered as pathogen related (PR) proteins, because they are produced in response to attack by the phytopathogens [60]. They are induced by growth regulators or elicitors such as chitooligosaccharides. The acidic PR proteins are induced by salicylic acid while basic PR proteins are induced by ethylene. Their activity is also induced in response to stresses like high salt concentration, cold, drought, wounding and sometimes also by heavy metal salts [14,17,61,62].

These chitinases play important role in physiological processes of plants like growth and development process. Many plant chitinases have been isolated, purified and studied. Garg and Gupta (2010) reported isolation and purification of chitinase from moth beans against fungal pathogen [63]. Purification of chitinase from Euphorbia characias has been reported which is stable up to $60^{\circ} \mathrm{C}$ temperature [64]. Chitinases from various other plants like Vigna mungo, Vicia faba and Glycine max have also been isolated and purified [65,66,67]. These enzymes also play role in regulation of nodulation by signal molecules $[62,68]$.

\section{Insect Chitinases}

Insect chitinases belong to family 18 of glycosyl hydrolases and are reported in all insect species belonging to different orders like lepidopterans, hemipterans, dipterans, hymenopterans and coleopterans [23]. Although family 18 chitinases have experienced large evolutionary change from prokaryotes to eukaryotes but the most considerable increase in the number of chitinase coding genes appears to have arisen within insects $[23,69]$. Many chitinases have been isolated and purified from insect cell lines, gut, hemolymph, and venom of a wasp where these enzymes act as degradative enzymes.

Domain architecture of insect chitinases has a multi-domain structure including various domains like catalytic domain, serine/threonine enriched linker region and cysteine enriched chitin binding domain. In addition, they also have a trans-membrane spanning domain. On the basis of conserved sequences and specific domains, insect chitinases are divided into eight groups with distinct domain architecture. The chitinases of group I have one catalytic domain, one carboxy terminal chitin binding domain and a signal peptide. The group II contains chitinases of high molecular weight with a signal peptide, four to seven chitin binding domains and four to five catalytic domains. Group III chitinases consist of a transmembrane span at $\mathrm{N}$-terminal region, one chitin binding domain and two catalytic domains. The most divergent and largest group is group IV, having one catalytic domain and a signal peptide. Most of the chitinases of this group lack a chitin binding domain 
(CBD). Group V chitinases are consisted of a catalytic domain, conserved motifs and a peptide but CBD is absent in them while chitinases of group VI have one CBD and one catalytic domain. Group VII chitinases have a signal peptide, one catalytic domain and lack chitin binding domain while group VIII enzymes are consisted of chitinases having a transmembrane span at $\mathrm{N}$-terminal region, single catalytic domain and absence of CBD [23].

During ecdysis, cuticle of insects is cleaved into chito-oligomers by the action of endochitinases, and these chito-oligomers are further hydrolyzed to $\mathrm{N}$-acetyl-glucosamine monomers by exochitinases. These monomers are used in the synthesis of new cuticle. Therefore, insect chitinases play a main role in defense against their own parasites. During transformation of larvae, hormones regulate the production of these enzymes. These chitinases are reported to have molecular weight ranging from 40,000 to 80,000 daltons $[14,17]$.

There are reports of inhibition of insect chitinases by substrate/products as well as analogs of transition state. The allosamidin is a compound produced by streptomyces species, and it causes inhibition of family 18 chitinases but not of family 19 chitinases. The insect chitinases belong to family 18; and therefore, are inhibited by allosamidin $[70,71,72]$.

\section{Mammalian Chitinases}

Mammalian chitinases belong to family 18 of glycosyl hydrolases. Chitin is not found in mammals, however, carbohydrates having identical structure as that of chitin like hyaluronic acid and heparin sulfate are used as a substrate for mammalian chitinases [28]. At least 7 chitinases of family 18 have been identified in mammals. Mammalian chitinases are further classified as true chitinases and chitinases like proteins (ClPs). Only true chitinases have enzymatic activity and they degrade chitin while CLPs don't have enzymatic activity [14,73]. True chitinases also possess a carboxyl terminal chitin binding domain [74]. Chitotrisidase and acidic mammalian chitinase (AMCase) belong to true chitinases category and both contain a catalytic and chitin binding domains [5]. Chitotrisidase is antifungal in nature and is produced in macrophages and expressed in Gauchers cells while AMCase is produced by eosinophils, macrophages and epithelial cells $[14,28]$.

In mammals, these chitinases are expressed in higher amount during infection suggesting that they contribute their potential to host defense [75]. These enzymes when enzymatically active show specific pattern during different disorders. Therefore, these can be used as markers for detection and study of various inflammatory and malignant disorders [74]. Various studies of arthritis, cancer and liver fibrosis have suggested that chitinase 3-like protein has significant role in inflammation and tissue remodeling $[17,28]$.

\section{Applications of Chitinases}

Chitinases are used for the biodegradation of chitin into beneficial components. They can be exploited for controlling insect and fungal pathogens of plants and hence can be used as agents for crop protection. Chitinases from different sources act as a fungicidal compound like bacterial chitinases while many are antifungal in properties. They may be exploited in agriculture and environmental uses, cosmetics and food technology $[17,76]$. They can also be used for detecting the population of fungi in soil [77]. The chitinases may be exploited for following commercial applications:

\section{Bio-Control of Phytopathogens}

Chitinolytic micro-organisms and their enzymes are useful in controlling insects and phytopathogens offering a valid approach for agriculture $[10,14]$. The fungus, $T$. harzianum exhibit much higher chitinase activity and therefore, is used to reduce the population of insects and acts as a biocontrol agent $[4,78]$. The most important plant pathogens are Fusarium, Alternaria and Aspergillus. These pathogens attack many crops and therefore, chitinases are used for crop protection [52]. Many bacterial chitinases like from Bacillus pumilus [79], Stenotrophomonas maltophilia [37], Streptomyces hygroscopicus [36] and Bacillus subtilis [80] are reported to have fungicidal properties. Due to the role of chitinase in fungal growth and development, it is gaining attention as biocontrol agent [81]. The causative agent of witch's broom disease of cocoa is destroyed by T. harzianum chitinase [82].

\section{Potential as Bio-Pesticides}

Insects and crustaceans belonging to the phylum, arthropod are the major pests distributed all over the ecosystems. Because of harmful effects and high cost of chemical pesticides, biopesticides being eco-friendly are becoming more popular. The gut lining and exoskeleton of insects is made up of chitin $[2,83]$. Insects have a chitinous cuticle, and therefore, chitinase can be used to degrade the cuticle [15]. Chitinases are getting attention as biopesticide because of their physiological role in nematode and insect [81]. Insect chitinases can also be used as biopesticides in transgenic plants [23]. Chitinase also inhibits the egg hatching of root knot nematode [84]. The biological role of fungal chitinases in rupturing nematode eggs has been reported [19]. The Bacillus thuringiensis also produces chitinase and endotoxin against the insects [15].

\section{Production of Single Cell Protein}

Single cell proteins (SCP) can be utilized as a protein dietary additive and can reinstate expensive traditional protein sources such as fish meal and soymeal $[85,86]$. Shell fish waste is an abundant source of calcium carbonate, 
protein and chitin. Various investigations reported that chitinolytic enzyme produced from S. marcescens and Pichia kudriavzevii, degraded chitin and produced SCPs. The yield of generated single cell proteins was $45 \%$ protein and $8-11 \%$ nucleic acids [86].

Shell fish solid waste mainly contains chitin, which can be degraded by the action of chitinase to produce single cell protein (SCP) [2]. Fungi generally used as a source of SCP are Candida tropicalis, Saccharomyces cerevisiae, Hansenula polymorpha and Myrothecium verrucaria. The chitinases from these fungi are used for production of SCP from chitinous waste. The production of chitinase enzyme from S. cerevisiae showed better results. Here the SCP produced was more than $60 \%$ and had lesser nucleic acid contents ranging from 1 to $3 \%$. Evaluation of SCP production is based on total nucleic acid contents, protein amount and growth yield [2,14]. Chitinase from Penicillium ochrochloron MTCC 517 and Yarrnowia lipolytica NCIM 3450 was used for hydrolysis of chitin and generation of N-Acetyl-D-glucosamine and SCPs. It was found that chitin (2\%) provided optimum yield of SCP with a maximum yield of $2.9 \%$ nucleic acid and $65 \%$ protein, from biomass of $9.4 \mathrm{~g} / \mathrm{l}[86,87]$.

\section{Fungal Biomass Estimation}

There are a number of ways like microscopic observation and extraction of specific indicator to estimate fungi present in soil. There is a correlation between the growth of fungus in soil and chitinase enzyme activity. Therefore, chitinase activity may be used as an indicator for the fungal growth in soil [77]. Determining chitinase activity gives a rapid, simple and sensitive measure of fungal biomass in soil [88]. Chitinase activity may be used as an indicator for infection of fungus in human [2].

\section{Medical Applications}

Chitinases have a huge potential in medical and pharmaceutical fields. Chitinases are used as additive in order to increase the efficiency of antifungal drugs for treatment of fungal infections [14,17]. Chitinase can also be used in skin lotions and antifungal creams as additives [2]. In addition, there are many other medical applications for chitinases. Acid mammalian chitinase (AMCase) causes inhibition of chitin induced innate inflammation and allergen induced inflammation [75]. Their overproduction can be linked to asthma disease [89]. Certain chitinase like proteins inhibit lung injury induced by the oxidant. They also regulate cell death and help in wound healing [28]. Chitotriosidase can be used as a marker because of its increased expression level in diseases like Gaucher's diseases, fungal and bacterial infections, malaria, liver disease and certain neuro degenerative diseases [28]. Human chitinases and chitinase like proteins act as indicator for inflammation and cancer [74]. It has been reported that cell surface of cultured cancer cells upon treatment with chitinase gets damaged. Since, chitin is not present in normal mammalian cell so treatment with chitinase will not cause any injury or adverse effect to them [90,91]. Lysosomal disorders can be evaluated by using chitotriosidase activity as an indicator [92]. They act as marker for monitoring various therapeutic approaches for diseases [93]. Chitinases can also be used in wound healing, nerve generation and drug delivery [76].

\section{Production of Oligomers}

The oligomers of chitin have very important role in medical as well as pharmaceutical fields. Chitin is degraded by chitinase and forms different types of oligosaccharides like N-acetylglucosamine, chitooligosaccharides, glucosamine and chitosan. These oligosaccharides act as elicitors of plant defense, and are also used in human medicines as drug against inflammation. Shen et al.-reported that chitooligosaccharides inhibited tumor growth indicating their antitumor function [94]. They are also used in food preservation [95]. Therefore, one can use chitinase enzyme in various combinations to get required oligomers [2].

\section{Mosquito Control}

The global socioeconomic situation of diseases caused by mosquitoes made them potential targets for various pest control agents. Control of mosquitoes using chemical pesticides has different adverse effects like environmental pollution and development of resistance in the target species. Therefore, attempts have been made to overcome this problem by using biocontrol agents. Cuticle of mosquito is made up of chitin, and hence chitinases can also be used in mosquito control. Many mosquitoes are found to be affected by chitinase. Dengue and yellow fever are caused by a vector, Aedes aegypti. Entomopathogenic fungus can't infect this vector but chitinase produced from Myrothecium verrucaria killed its larvae. M. verrucaria (saprophytic fungus) produces insect cuticle degrading chitinase which has been effective against both first and fourth instar mosquito larvae of A. aegypti. The time required to kill larvae decreases if purified chitinase is used $[2,14,96]$. Improvement of the insecticidal activity by expression of chitinase gene ChitC in Bacillus sphaericus has also been reported against resistant Culex quinquefasciatus. The enhanced toxicity of recombinant strain has been considered due to the result of synergy between chitinase and binary toxins produced [97].

\section{Waste Management}

Chitinous biomass can be converted into useful simpler components by utilizing genetically modified chitinases minimizing water pollution. Chitinases degrade chitin into 
chitooligosaccharides which have a broad range of biotechnological applications in various industries like biochemical, food and pharmaceutical sectors [98]. Chitinous waste also serves as a substrate for chitinase production in many industries where various bacterial species and actinomycetes utilize shrimp shells for production of chitinase [52].

Chitinase are used in degradation of shell fish waste to produce N-acetyl-D-glucosamine which is useful in manufacturing of food products, chemicals, growth factors and medicines $[14,99]$. Chitinous waste can also be used in efficient production of single cell proteins after treatment with chitinase. It is used as carbon and nitrogen source for biomass production. Various studies have reported application of chitinase in bioconversion of chitinous waste. A novel chitinase (PbChi67) isolated from Paenibacillus barengoltzii CAU904 has been reported as a good candidate for chitinous waste management [100]. Purification and characterization of chitinase from Streptomyces anulatus CS242 has been reported where the enzyme showed potential for biodegradation of chitin waste (shrimp shell) [101]. The recycling of chitin waste (fungal biomass) by chitinase producing Streptomyces sp. M1 has also been suggested [102]. Enhanced extracellular production of chitinase from soil microbe Pseudomonas fluorescens for degradation of chitin waste (shrimp shells) has also been reported [103]. Complete biodegradation of shrimp waste by a novel marine bacteria Paenibacillus sp. $\mathrm{AD}$ has also been reported [104]. Production of $\mathrm{N}$-acetyl-D-glucosamine from chitin waste utilizing chitinase from Aspergillus terreus has been reported where fungus was isolated from marine environment and the chitinase was used for biotransformation of chitinaceous waste [29]. Use of a chitinase from Aspergillus niger (AnChiB) has been observed for bioconversion of fungal mycelial waste into $\mathrm{N}$-acetyl-D-glucosamine [105]. Wang et al. (2020) studied the high efficiency production and directed evolution of chitinase BcChiA1 in Bacillus subtilis and utilized it for bioconversion of chitinous wastes into chitooligomers [106].

\section{Conclusions}

The knowledge about immense diversity of chitin degrading enzymes would be beneficial for the novel chitinase identification and later in biodegradation of large chitin enriched biomass. In the past decades, a large number of investigations have been conducted on chitinases and they have been isolated, purified and characterized from different sources. Chitinase having the capability of being exploited for enormous industrial applications, is a good candidate for applied research. There is need of novel chitinases having more efficiency and methods for purification for better yields. Approaching source of new chitinase is archaebacteria as they are extreme thermophiles so they can produce chitinase with more thermostability. Chitinases can also be exploited in food preservation and may be considered as anti-tumor drug for treatment of cancer. The future research on chitinase must be focused in the fields of medicine and waste management. Isolation of chitinase can also be done from plant waste as it would be a novel approach. Immobilization of chitinase can also be considered to reduce the cost during its industrial applications. Genetic engineering and protein engineering approaches can also be employed to construct novel chitinases. Cost effective and practical usage of chitinases can be accomplished by improvement of catalytic activity or increased yield of chitinase.

\section{Acknowledgements}

Authors acknowledge the facilities of the Department of Biotechnology, Ministry of Science and Technology, Government of India, New Delhi (DBT) under the Bioinformatics Sub Centre and M.Sc. Biotechnology program present in our Department and used in the present work.

\section{Conflict of Interest}

The authors have no conflict of interest.

\section{REFERENCES}

[1] Text Book of Enzymes and Enzyme Technology (2015) by Anil Kumar and Sarika Garg, MV Learning, London, United Kingdom.

[2] Dahiya, N., Tewari, R. and Hoondal, G. S. (2006). Biotechnological aspects of chitinolytic enzymes: a review. Applied Microbiology and Biotechnology, 71(6), 773-782.

[3] Yan, Q. and Fong, S. S. (2015). Bacterial chitinase: nature and perspectives for sustainable bioproduction.Bioresource $s$ and Bioprocessing, 2(1), 1-9.

[4] Duo-Chuan, L. (2006). Review of fungal chitinases. Mycopathologia, 161(6), 345-360.

[5] Barad, B. A., Liu, L., Diaz, R. E., Basilio, R., Van Dyken, S. J., Locksley, R. M. and Fraser, J. S. (2019). Differences in the chitinolytic activity of mammalian chitinases on soluble and crystalline substrates. BioRxiv, 762336.

[6] Kuzu, S. B., Güvenmez, H. K. and Denizci, A. A. (2012). Production of a thermostable and alkaline chitinase by Bacillus thuringiensis subsp. kurstaki strain HBK-51. Biotechnology Research International, 2012.

[7] Roncero, C., and Vázquez de Aldana, C. R. (2019). Glucanases and Chitinases. In Current Topics in Microbiology and Immunology. Springer, Berlin, 
Heidelberg.

[8] Kadowaki, S., Saskiawan, I., Watanabe, J., Yamamoto, K., Bunno, M., Ichihara, Y. and Kumagai, H. (1997). Transglycosylation activity of $\beta$ - $\mathrm{N}$-acetylhexosaminidase from Penicillium oxalicum and its application to synthesis of a drug carrier. Journal of Fermentation and Bioengineering, 83(4), 341-345.

[9] Annamalai, N., Giji, S., Arumugam, M. and Balasubramanian, T. (2010). Purification and characterization of chitinase from Micrococcus sp. AG84 isolated from marine environment. African Journal of Microbiology Research, 4(24), 2822-2827.

[10] Zhou, J., Chen, J., Xu, N., Zhang, A., Chen, K., Xin, F., Zhang, W., Ma, J., Fang, Y., Jiang, M. and Dong, W. (2019). The broad-specificity chitinases: their origin, characterization, and potential application. Applied Microbiology and Biotechnology, 103(8), 3289-3295.

[11] Krishnaveni, B. and Ragunathan, R. (2014). Chitinase production from seafood wastes by plant pathogen Bionectria CBNR BKRR sps. and its application in bioremediation studies. International Research Journal of Medical Sciences, 2(11), 15-19.

[12] Jahromi, S. T. and Barzkar, N. (2018). Marine bacterial chitinase as sources of energy, eco-friendly agent, and industrial biocatalyst. International Journal of Biological Macromolecules, 120, 2147-2154.

[13] Herdyastuti, N., Raharjo, T. J., Mudasir, M. and Matsjeh, S. (2009). Chitinase and chitinolytic microorganism: Isolation, characterization and potential. Indonesian Journal of Chemistry, 9(1), 37-47.

[14] Roopavathi, A. S., Vigneshwari, R. and Jayapradha, R. (2015). Chitinase: production and applications. Journal of Chemical and Pharmaceutical Research, 7(5), 924-931.

[15] Stoykov, Y. M., Pavlov, A. I. and Krastanov, A. I. (2015). Chitinase biotechnology: production, purification, and application. Engineering in Life Sciences, 15(1), 30-38.

[16] Lee, Y. G., Chung, K. C., Wi, S. G., Lee, J. C. and Bae, H. J. (2009). Purification and properties of a chitinase from Penicillium sp. LYG 0704. Protein Expression and Purification, 65(2), 244-250.

[17] Hamid, R., Khan, M. A., Ahmad, M., Ahmad, M. M., Abdin, M. Z., Musarrat, J. and Javed, S. (2013). Chitinases: an update. Journal of Pharmacy and Bio-allied Sciences, 5(1), 21.

[18] Das, S., Roy, D. and Sen, R. (2016). Utilization of chitinaceous wastes for the production of chitinase. In Advances in Food and Nutrition Research, 78, 27-46.

[19] Gortari, M. C. and Hours, R. A. (2008). Fungal chitinases and their biological role in the antagonism onto nematode eggs: A review. Mycological progress, 7(4), 221-238.

[20] Beygmoradi, A., Homaei, A., Hemmati, R., Santos-Moriano, P., Hormigo, D. and Fernández-Lucas, J. (2018). Marine chitinolytic enzymes, a biotechnological treasure hidden in the ocean? Applied Microbiology and Biotechnology, 102(23), 9937-9948.

[21] Paulsen, S. S., Andersen, B., Gram, L. and Machado, H. (2016). Biological potential of chitinolytic marine bacteria.
Marine drugs, 14(12), 230.

[22] Sørlie, M., Horn, S. J., Vaaje-Kolstad, G. and Eijsink, V. G. (2020). Using chitosan to understand chitinases and the role of processivity in the degradation of recalcitrant polysaccharides. Reactive and Functional Polymers, 148, 104488.

[23] Arakane, Y. and Muthukrishnan, S. (2010). Insect chitinase and chitinase-like proteins. Cellular and Molecular Life Sciences, 67(2), 201-216.

[24] Patil, R. S., Ghormade, V. and Deshpande, M. V. (2000). Chitinolytic enzymes: an exploration. Enzyme and Microbial Technology, 26(7), 473-483.

[25] Júnior, J. E. M., Grangeiro, T. B. and Nogueira, N. A. P. (2018). Chitinases as antibacterial proteins: a systematic review. Journal of Young Pharmacists, 10(2), 144-148.

[26] Renner, T. and Specht, C. D. (2013). Inside the trap: gland morphologies, digestive enzymes, and the evolution of plant carnivory in the Caryophyllales. Current Opinion in Plant Biology, 16(4), 436-442.

[27] Adams, D. J. (2004). Fungal cell wall chitinases and glucanases. Microbiology, 150(7), 2029-2035.

[28] Lee, C. G., Da Silva, C. A., Dela Cruz, C. S., Ahangari, F., Ma, B., Kang, M. J., He, C.H., Takyar, S. and Elias, J. A. (2011). Role of chitin and chitinase/chitinase-like proteins in inflammation, tissue remodelling, and injury. Annual Reviews of Physiology, 73, 479-501.

[29] Das, S., Dey, P., Roy, D., Maiti, M. K. and Sen, R. (2019). $\mathrm{N}$-Acetyl-D-glucosamine production by a Chitinase of marine fungal origin: a case study of potential industrial significance for valorization of waste chitins. Applied Biochemistry and Biotechnology, 187(1), 407-423.

[30] Tran, D. M., Sugimoto, H., Nguyen, D. A., Watanabe, T. and Suzuki, K. (2018). Identification and characterization of chitinolytic bacteria isolated from a freshwater lake. Bioscience, Biotechnology and Biochemistry, 82(2), 343-355.

[31] Kim, Y. H., Park, S. K., Hur, J. Y. and Kim, Y. C. (2017). Purification and characterization of a major extracellular chitinase from a biocontrol bacterium, Paenibacillus elgii HOA73. The Plant Pathology Journal, 33(3), 318.

[32] Nguyen-Thi, N. and Doucet, N. (2016). Combining chitinase $\mathrm{C}$ and N-acetylhexosaminidase from Streptomyces coelicolor A3 (2) provides an efficient way to synthesize $\mathrm{N}$-acetylglucosamine from crystalline chitin. Journal of Biotechnology, 220, 25-32.

[33] Bhattacharya, S., Das, A., Samadder, S. and Rajan, S. S. (2016). Biosynthesis and characterization of a thermostable, alkali-tolerant chitinase from Bacillus pumilus JUBCH08 displaying antagonism against phytopathogenic Fusarium oxysporum. 3 Biotech, 6(1), 87.

[34] Esawy, M. A., Awad, G. E., Wahab, W. A. A., Elnashar, M. M., El-Diwany, A., Easa, S. M. and Fawkia, M. (2016). Immobilization of halophilic Aspergillus awamori EM66 exochitinase on grafted k-carrageenan-alginate beads. 3 Biotech, 6(1), 29.

[35] Liu, Y., Chan, Z. and Zeng, R. (2015). Purification and characterization of chitinase secreted by Pseudoalteromonas 
sp. DXK012 isolated from deepsea sediment. Journal of Natural Science, 1, e37.

[36] Haggag, W. M. and Abdallh, E. (2012). Purification and characterization of chitinase produced by endophytic Streptomyces hygroscopicus against some phytopathogens. Journal of Microbiology Research, 2(5), 145-151.

[37] Jankiewicz, U., Brzezinska, M. S. and Saks, E. (2012). Identification and characterization of a chitinase of Stenotrophomonas maltophilia, a bacterium that is antagonistic towards fungal phytopathogens. Journal of Bioscience and Bioengineering, 113(1), 30-35.

[38] Ramli, A. N., Mahadi, N. M., Rabu, A., Murad, A. M., Bakar, F. D. and Illias, R. M. (2011). Molecular cloning, expression and biochemical characterisation of a cold-adapted novel recombinant chitinase from Glaciozyma antarctica PI12. Microbial Cell Factories, 10(1), 1-13.

[39] Liu, T., Guo, X., Bu, Y., Zhou, Y., Duan, Y. and Yang, Q. (2020). Structural and biochemical insights into an insect gut-specific chitinase with antifungal activity. Insect Biochemistry and Molecular Biology, 119, 103326.

[40] Solanki, D. S., Kumar, S., Parihar, K., Sharma, K., Gehlot, P., Singh, S. K. and Pathak, R. (2018). Purification and characterization of a novel thermostable antifungal protein with chitinase activity from mung bean. Journal of Environmental Biology, 39(3), 406-412.

[41] Kabir, S. R., Rahman, M. M., Tasnim, S., Karim, M. R., Khatun, N., Hasan, I., Amin, R., Islam, S.S., Nurujjaman, M., Kabir, A.H. and Sana, N. K. (2016). Purification and characterization of a novel chitinase from Trichosanthes dioica seed with antifungal activity. International Journal of Biological Macromolecules, 84, 62-68.

[42] Sharma, B., Gupta, R., Sahoo, D. and Deswal, R. (2019). Purification of dual-functioning chitinases with hydrolytic and antifreeze activities from Hippophae rhamnoides seedlings. Journal of Proteins and Proteomics, 10(1), 69-81.

[43] Kimura, M., Umeyama, T., Wakita, S., Okawa, K., Sakaguchi, M., Matoska, V.,Bauer, P.O. and Oyama, F. (2019). Direct comparison of chitinolytic properties and determination of combinatory effects of mouse chitotriosidase and acidic mammalian chitinase. International Journal of Biological Macromolecules, 134, 882-890.

[44] Huber, R., Stöhr, J., Hohenhaus, S., Rachel, R., Burggraf, S., Jannasch, H. W., and Stetter, K. O. (1995). Thermococcus chitonophagus sp. nov., a novel, chitin-degrading, hyperthermophilic archaeum from a deep-sea hydrothermal vent environment. Archives of microbiology, 164(4), 255-264.

[45] Sorokin, D. Y. (2015). Halo (natrono) archaea isolated from hypersaline lakes utilize cellulose and chitin as growth substrates. Frontiers in microbiology, 6, 942.

[46] Tanaka, T., Fukui, T., Fujiwara, S., Atomi, H., and Imanaka, T. (2004). Concerted action of diacetylchitobiose deacetylase and exo- $\beta$-d-glucosaminidase in a novel chitinolytic pathway in the hyperthermophilic archaeon Thermococcus kodakaraensis KOD1. Journal of Biological Chemistry, 279(29), 30021-30027.

[47] Chen, L., Wei, Y., Shi, M., Li, Z., and Zhang, S. H. (2019).
An archaeal chitinase with a secondary capacity for catalyzing cellulose and its biotechnological applications in shell and straw degradation. Frontiers in microbiology, 10, 1253.

[48] Gong, C., SiMing, J., LiShi, R., Cui, F., JiYao, K., and YuGuang, D. (2018). Preparation of chitooligosaccharides with low degree of deacetylation by recombinant chitinase from Pyrococcus furiosus, its compositions and structure analysis. Shipin Kexue/Food Science, 39(18), 115-119.

[49] Morimoto, K. E. N. J. I., Karita, S. H. U. I. C. H. I., Kimura, T. E. T. S. U. Y. A., Sakka, K. A. Z. U. O. and Ohmiya, K. U. N. I. O. (1997). Cloning, sequencing, and expression of the gene encoding Clostridium paraputrificum chitinase ChiB and analysis of the functions of novel cadherin-like domains and a chitin-binding domain. Journal of Bacteriology, 179(23), 7306-7314.

[50] Metcalfe, A. C., Krsek, M., Gooday, G. W., Prosser, J. I. and Wellington, E. M. H. (2002). Molecular analysis of a bacterial chitinolytic community in an upland pasture. Applied Environmental Microbiology, 68(10), 5042-5050.

[51] Cohen-Kupiec, R. and Chet, I. (1998). The molecular biology of chitin digestion. Current Opinion in Biotechnology, 9(3), 270-277.

[52] Brzezinska, M. S., Jankiewicz, U., Burkowska, A. and Walczak, M. (2014). Chitinolytic microorganisms and their possible application in environmental protection. Current Microbiology, 68(1), 71-81.

[53] Dukariya, G. and Kumar, A. (2020). Chitinase Production from Locally Isolated Bacillus cereus GS02 from Chitinous Waste Enriched Soil. Journal of Advances in Biology and Biotechnology, 23(1), 39-48.

[54] Xia, J. L., Xiong, J., Zhang, R. Y., Liu, K. K., Huang, B. and Nie, Z. Y. (2011). Production of Chitinase and its Optimization from a Novel Isolate Serratia marcescens XJ-01. Indian Journal of Microbiology, 51(3), 301-306.

[55] Donderski, W. and Brzezinska, M. S. (2005). The Influence of Heavy Metals on the Activity of Chitinases Produced by Planktonic, Benthic and Epiphytic Bacteria. Polish Journal of Environmental Studies, 14(6), 851-859.

[56] Seidl, V. (2008). Chitinases of filamentous fungi: a large group of diverse proteins with multiple physiological functions. Fungal Biology Reviews, 22(1), 36-42.

[57] Tikhonov, V. E., Lopez-Llorca, L. V., Salinas, J. and Jansson, H. B. (2002). Purification and characterization of chitinases from the nematophagous fungi Verticillium chlamydosporium and V. suchlasporium. Fungal Genetics and Biology, 35(1), 67-78.

[58] Matsumoto, T., Inoue, H., Sato, Y., Kita, Y., Nakano, T., Noda, N., Eguchi-Tsuda, M., Moriwaki, A., Kan-o, K., Matsumoto, K. and Shimizu, T. (2009). Demethylallosamidin, a chitinase inhibitor, suppresses airway inflammation and hyperresponsiveness. Biochemical and Biophysical Research Communications, 390(1), 103-108.

[59] Agrawal, T. and Kotasthane, A.S. (2012) Chitinolytic assay of indigenous Trichoderma isolates collected from different geographical locations of Chhattisgarh in Central India. Springer Plus 1(1): 73. 
[60] Malik, A. (2019). Purification and properties of plant chitinases: A review. Journal of Food Biochemistry, 43(3), e12762.

[61] Kasprzewska, A. N. N. A. (2003). Plant chitinases-regulation and function. Cellular and Molecular Biology Letters, 8(3), 809-824.

[62] Eilenberg, H., Pnini-Cohen, S., Schuster, S., Movtchan, A. and Zilberstein, A. (2006). Isolation and characterization of chitinase genes from pitchers of the carnivorous plant Nepenthes khasiana. Journal of Experimental Botany, 57(11), 2775-2784.

[63] Garg, N. and Gupta, H. (2010). Isolation and purification of fungal pathogen (Macrophomina phaseolina) induced chitinase from moth beans (Phaseolus aconitifolius). Journal of Pharmacy and Bio-allied Sciences, 2(1), 38-43.

[64] Spano, D., Pospiskova, K., Safarik, I., Pisano, M. B., Pintus, F., Floris, G. and Medda, R. (2015). Chitinase III in Euphorbia characias latex: purification and characterization. Protein Expression and Purification, 116, 152-158.

[65] Sharma, S. and Hooda, V. (2018). Purification and analytical application of Vigna mungo chitinase for determination of total fungal load of stored cereals. Applied Biochemistry and Biotechnology, 186(1), 12-26.

[66] Wang, S., Ye, X., Chen, J. and Rao, P. (2012). A novel chitinase isolated from Vicia faba and its antifungal activity. Food Research International, 45(1), 116-122.

[67] Chang, Y. M., Chen, L. C., Wang, H. Y., Chiang, C. L., Chang, C. T. and Chung, Y. C. (2014). Characterization of an acidic chitinase from seeds of black soybean (Glycine max (L) Merr Tainan No. 3). PloS one, 9(12), 1-15.

[68] Goormachtig, S., Lievens, S., Van de Velde, W., Van Montagu, M. and Holsters, M. (1998). Srchi13, a novel early nodulin from Sesbania rostrata, is related to acidic class III chitinases. The Plant Cell, 10(6), 905-915.

[69] Karlsson, M. and Stenlid, J. (2009). Evolution of family 18 glycoside hydrolases: diversity, domain structures and phylogenetic relationships. Journal of Molecular Microbiology and Biotechnology, 16(3-4), 208-223.

[70] Koga, D., Isogai, A., Sakuda, S., Matsumoto, S., Suzuki, A., Kimura, S. and Ide, A. (1987). Specific inhibition of Bombyx mori chitinase by allosamidin. Agricultural and Biological Chemistry, 51(2), 471-476.

[71] Zhu, X., Zhang, H., Fukamizo, T., Muthukrishnan, S. and Kramer, K. J. (2001). Properties of Manduca sexta chitinase and its C-terminal deletions. Insect Biochemistry and Molecular Biology, 31(12), 1221-1230.

[72] Arakane, Y., Zhu, Q., Matsumiya, M., Muthukrishnan, S. and Kramer, K. J. (2003). Properties of catalytic, linker and chitin-binding domains of insect chitinase. Insect Biochemistry and Molecular Biology, 33(6), 631-648.

[73] Bussink, A. P., Speijer, D., Aerts, J. M. and Boot, R. G. (2007). Evolution of mammalian chitinase (-like) members of family 18 glycosyl hydrolases. Genetics, 177(2), 959-970.

[74] Kzhyshkowska, J., Gratchev, A. and Goerdt, S. (2007). Human chitinases and chitinase-like proteins as indicators for inflammation and cancer. Biomarker insights, 2, 128-146.
[75] Sutherland, T. E., Maizels, R. M. and Allen, J. E. (2009) Chitinases and chitinase - like proteins: potential therapeutic targets for the treatment of $\mathrm{T}$ - helper type 2 allergies. Clinical and Experimental Allergy, 39(7), 943-955.

[76] Manivasagan, P., Venkatesan, J., Sivakumar, K. and Kim, S. K. (2014). Pharmaceutically active secondary metabolites of marine actinobacteria. Microbiological Research, 169(4), 262-278.

[77] Miller, M., Palojärvi, A., Rangger, A., Reeslev, M. and Kjøller, A. (1998). The use of fluorogenic substrates to measure fungal presence and activity in soil. Applied Environmental Microbiology, 64(2), 613-617.

[78] Benítez, T., Rincón, A. M., Limón, M. C. and Codon, A. C. (2004). Biocontrol mechanisms of Trichoderma strains. International Microbiology, 7(4), 249-260.

[79] Ghasemi, S., Ahmadian, G., Jelodar, N. B., Rahimian, H., Ghandili, S., Dehestani, A. and Shariati, P. (2010). Antifungal chitinases from Bacillus pumilus SG2: preliminary report. World Journal of Microbiology and Biotechnology, 26(8), 1437-1443.

[80] Senol, M., Nadaroglu, H., Dikbas, N. and Kotan, R. (2014). Purification of Chitinase enzymes from Bacillus subtilis bacteria TV-125, investigation of kinetic properties and antifungal activity against Fusarium culmorum. Annals of Clinical Microbiology and Antimicrobials, 13(1), 1-7.

[81] Herrera-Estrella, A. and Chet, I. (1999). Chitinases in biological control. EXS-BASEL-, 87, 171-184.

[82] De Marco, J. L., Lima, L. H. C., de Sousa, M. V. and Felix, C. R. (2000). A Trichoderma harzianum chitinase destroys the cell wall of the phytopathogen Crinipellis perniciosa, the causal agent of witches' broom disease of cocoa. World Journal of Microbiology and Biotechnology, 16(4), 383-386.

[83] Okongo, R. N., Puri, A. K., Wang, Z., Singh, S. and Permaul, K. (2019). Comparative biocontrol ability of chitinases from bacteria and recombinant chitinases from the thermophilic fungus Thermomyces lanuginosus. Journal of Bioscience and Bioengineering, 127(6), 663-671.

[84] Jung, S. J., An, K. N., Jin, Y. L., Park, R. D., Kim, K. Y., Shon, B. K. and Kim, T. H. (2002). Effect of chitinase-producing Paenibacillus illinoisensis KJA-424 on egg hatching of root-knot nematode (Meloidogyne incognita). Journal of Microbiology and Biotechnology, 12(6), 865-871.

[85] Nasseri, A. T., Rasoul-Amini, S., Morowvat, M. H. and Ghasemi, Y. (2011). Single cell protein: production and process. American Journal of Food Technology, 6(2), 103-116.

[86] Le, B. and Yang, S. H. (2019). Microbial chitinases: Properties, current state and biotechnological applications. World Journal of Microbiology and Biotechnology, 35(9), 144.

[87] Patil, N. S. and Jadhav, J. P. (2014). Enzymatic production of N-acetyl-D-glucosamine by solid state fermentation of chitinase by Penicillium ochrochloron MTCC 517 using agricultural residues. International Biodeterioration and Biodegradation, 91, 9-17. 
[88] Halder, S. K., Pal, S. and Mondal, K. C. (2019). Biosynthesis of fungal chitinolytic enzymes and their potent biotechnological appliances. In Recent Advancement in White Biotechnology Through Fungi, pp. 281-298, Springer, Cham.

[89] Elias, J. A., Homer, R. J., Hamid, Q. and Lee, C. G. (2005). Chitinases and chitinase-like proteins in TH2 inflammation and asthma. Journal of Allergy and Clinical Immunology, 116(3), 497-500.

[90] Pan, X. Q., Shih, C. C. and Harday, J. (2005). Chitinase induces lysis of MCF-7 cells in culture and of human breast cancer xenograft B11-2 in SCID mice. Anticancer Research, 25(5), 3167-3172.

[91] Abu-Tahon, M. A. and Isaac, G. S. (2020). Anticancer and antifungal efficiencies of purified chitinase produced from Trichoderma viride under submerged fermentation. The Journal of General and Applied Microbiology, 66(1), 32-40.

[92] Ries, M., Schaefer, E., Lührs, T., Mani, L., Kuhn, J., Vanier, M. T., Krummenauer, F., Gal, A., Beck, M. and Mengel, E. (2006). Critical assessment of chitotriosidase analysis in the rational laboratory diagnosis of children with Gaucher disease and Niemann-Pick disease type A/B and C. Journal of Inherited Metabolic Disease: Official Journal of the Society for the Study of Inborn Errors of Metabolism, 29(5), 647-652.

[93] Pastores, G. M., Barnett, N. L. and Kolodny, E. H. (2005). An open-label, noncomparative study of miglustat in type I Gaucher disease: efficacy and tolerability over 24 months of treatment. Clinical Therapeutics, 27(8), 1215-1227.

[94] Shen, K. T., Chen, M. H., Chan, H. Y., Jeng, J. H. and Wang, Y. J. (2009). Inhibitory effects of chitooligosaccharides on tumor growth and metastasis. Food and Chemical Toxicology, 47(8), 1864-1871.

[95] Muzzarelli, R. A., Boudrant, J., Meyer, D., Manno, N., DeMarchis, M. and Paoletti, M. G. (2012). Current views on fungal chitin/chitosan, human chitinases, food preservation, glucans, pectins and inulin: A tribute to Henri Braconnot, precursor of the carbohydrate polymers science, on the chitin bicentennial. Carbohydrate Polymers, 87(2), 995-1012.

[96] Thakur, N., Nath, A. K., Chauhan, A., Parmar, S. C., Pandey, H. and Thakur, K. (2019). Chitinases from microbial sources, their role as biocontrol agents and other potential applications. Journal of Entomology and Zoology Studies, 7(1): 837-843.

[97] Cai, Y., Yan, J., Hu, X., Han, B., and Yuan, Z. (2007).
Improving the insecticidal activity against resistant Culex quinquefasciatus mosquitoes by expression of chitinase gene chiAC in Bacillus sphaericus. Applied and environmental microbiology, 73(23), 7744-7746.

[98] Nunes, C. S. and Philipps-Wiemann, P. (2018). Chitinases. In Enzymes in Human and Animal Nutrition, pp. 361-378, Academic Press.

[99] Felse, P. A. and Panda, T. (2000). Production of microbial chitinases-A revisit. Bioprocess Engineering, 23(2), 127-134.

[100] Fu, X., Yan, Q., Wang, J., Yang, S. and Jiang, Z. (2016). Purification and biochemical characterization of novel acidic chitinase from Paenicibacillus barengoltzii. International Journal of Biological Macromolecules, 91, 973-979.

[101] Mander, P., Cho, S. S., Choi, Y. H., Panthi, S., Choi, Y. S. Kim, H. M. and Yoo, J. C. (2016). Purification and characterization of chitinase showing antifungal and biodegradation properties obtained from Streptomyces anulatus CS242. Archives of Pharmaceutical Research, 39(7), 878-886.

[102] Sukalkar, S. R., Kadam, T. A. and Bhosale, H. J. (2017), Isolation of chitinase producing Streptomyces sp. M1 for recycling of fungal biomass. International Journal of Scientific Research Science and Technology, 3(8), 399-404.

[103] Alhasawi, A. and Appanna, V. D. (2017). Enhanced extracellular chitinase production in Pseudomonas fluorescens: biotechnological implications. AIMS Bioengineering, 4, 366-375.

[104] Kumar, A., Kumar, D., George, N., Sharma, P. and Gupta, N. (2018). A process for complete biodegradation of shrimp waste by a novel marine isolate Paenibacillus sp. AD with simultaneous production of chitinase and chitin oligosaccharides. International Journal of Biological Macromolecules, 109, 263-272.

[105] Liu, T., Han, H., Wang, D., Guo, X., Zhou, Y., Fukamizo, T. and Yang, Q. (2020). Potent Fungal Chitinase for the Bioconversion of Mycelial Waste. Journal of Agricultural and Food Chemistry, 68(19), 5384-5390.

[106] Wang, S., Fu, G., Li, J., Wei, X., Fang, H., Huang, D., Lin, J. and Zhang, D. (2020). High-Efficiency Secretion and Directed Evolution of Chitinase BcChiA1 in Bacillus subtilis for the Conversion of Chitinaceous Wastes into Chitooligosaccharides. Frontiers in Bioengineering and Biotechnology, 8, 432. 